\title{
World War II, tantalum, and the evolution of modern cranioplasty technique
}

\author{
Patrick Flanigan, B.S., ${ }^{1}$ Varun R. Kshettry, M.D., ${ }^{2}$ and Edward C. Benzel, M.D. ${ }^{2}$ \\ ${ }^{1}$ Cleveland Clinic Lerner College of Medicine; and ${ }^{2}$ Department of Neurosurgery, Neurological Institute, \\ Cleveland Clinic, Cleveland, Ohio
}

\begin{abstract}
Cranioplasty is a unique procedure with a rich history. Since ancient times, a diverse array of materials from coconut shells to gold plates has been used for the repair of cranial defects. More recently, World War II greatly increased the demand for cranioplasty procedures and renewed interest in the search for a suitable synthetic material for cranioprostheses. Experimental evidence revealed that tantalum was biologically inert to acid and oxidative stresses. In fact, the observation that tantalum did not absorb acid resulted in the metal being named after Tantalus, the Greek mythological figure who was condemned to a pool of water in the Underworld that would recede when he tried to take a drink. In clinical use, malleability facilitated a single-stage cosmetic repair of cranial defects. Tantalum became the preferred cranioplasty material for more than 1000 procedures performed during World War II. In fact, its use was rapidly adopted in the civilian population. During World War II and the heyday of tantalum cranioplasty, there was a rapid evolution in prosthesis implantation and fixation techniques significantly shaping how cranioplasties are performed today. Several years after the war, acrylic emerged as the cranioplasty material of choice. It had several clear advantages over its metallic counterparts. Titanium, which was less radiopaque and had a more optimal thermal conductivity profile (less thermally conductive), eventually supplanted tantalum as the most common metallic cranioplasty material. While tantalum cranioplasty was popular for only a decade, it represented a significant breakthrough in synthetic cranioplasty. The experiences of wartime neurosurgeons with tantalum cranioplasty played a pivotal role in the evolution of modern cranioplasty techniques and ultimately led to a heightened understanding of the necessary attributes of an ideal synthetic cranioplasty material. Indeed, the history of tantalum cranioplasty serves as a model for innovative thinking and adaptive technology development.
\end{abstract} (http://thejns.org/doi/abs/10.3171/2014.2.FOCUS13552)

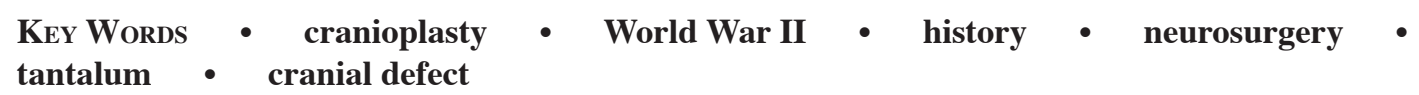

$\mathrm{C}$ RANIOPLASTY, the surgical repair of skull defects, has a long and rich history with much diversity not only regarding the breadth of materials that have been used in the procedure, but also in the techniques that were developed, modified, and discarded. The World War II era represents a pivotal point in the history of the cranioplasty procedure. The surge in traumatic cranial defects and deformities spurred an evolution in cranioplasty materials and surgical techniques. Tantalum represented a major breakthrough in synthetic cranioplasty implants. In fact, it became the material of choice for cranioplasty during World War II. There are several interesting historical facets and lessons that arose from tantalum's use in the wartime era. During this time, there was a rapid evolution in implant fixation techniques. The experience of neurosurgeons with tantalum for cranioplasty also refined their appreciation of the attributes of an ideal synthetic material for cranioplasty. While tantalum plates did not enjoy an enduring use as cranioprostheses, their use did change the way neurosurgeons, at the time, thought about the procedure. Hence, the story of the rise and fall of tantalum use serves as a lesson in innovation and innovative thinking.

Abbreviations used in this paper: $\mathrm{EEG}=$ electroencephalography; PMMA = polymethylmethacrylate.

\section{Evolution of Cranioplasty}

\section{Early Development}

Substantial evidence suggests that cranioplasty was performed in ancient and possibly prehistoric civilizations. While trephination was much more common, some cranioplasties are believed to have been performed by Incan surgeons using materials such as gourds, shells, and gold and silver plates during 3000-2000 BC. ${ }^{4}$ It is also speculated that skull fragments, known as "rondelles," may have been used by ancient Europeans for cranioplasty. ${ }^{53}$ Fallopius $(1523-1562)$ is credited with the first true description of a cranioplasty. In his description of the management of cranial fractures, he recommended the removal of bone surrounding a cranial fracture in cases of dural violation and replacement with a gold plate. ${ }^{59} \mathrm{In}$ the 16th century, various materials as diverse as ox horn, hard rubber, and sheet mica were used for cranioplasty, each with varying rates of success. ${ }^{76}$ The earliest instance of a cranioplasty utilizing a bone graft was performed in Moscow. The story was reported by Job Janszoon van Meekeren in 1668. A portion of the skull from a deceased dog was used to successfully repair a cranial defect in a nobleman. ${ }^{59}$ The graft was successful, and the patient returned to normal health. However, the graft was later 


\section{P. Flanigan, V. R. Kshettry, and E. C. Benzel}

removed because of the opposition by the church citing that the use of an animal's bone was marring God's image. ${ }^{27,51}$ Aside from some cranioplasties performed by the native South Sea populations using coconut shells, few cranioplasties were recorded for more than 200 years after van Meekeren's report. ${ }^{18}$

\section{Autograft Cranioplasty}

In the mid-19th century, Ollier (1859) and Macewen (1873) described and popularized the use of autograft for cranioplasty. ${ }^{27,39,59}$ In 1890, Müller generated a single flap of scalp, pericranium, and outer table calvaria from the region adjoining a cranial defect. ${ }^{47}$ Later that year, König refined this method by describing the use of twin flaps. ${ }^{33,60}$ The Müller-König method became the most used cranioplasty technique for about a decade (Fig. 1). The main shortcoming of this technique was poor cosmesis from both the rotation of scalp flaps and the depression overlying the outer table donor site. In 1903, von Hacker improved the scalp cosmesis of the Müller-König method by only shifting the periosteum and outer table from the bone surrounding the cranial defect (Fig. 2) ${ }^{76}$ In the 1900s, the von Hacker technique quickly became the most popular method of cranioplasty.

Soon after local autograft became popular, various authors attempted to obtain free autograft from various sources such as the sternum, scapula, ribs, ilium, and tibia. ${ }^{15,47,58,59}$ By 1909 , osteoperiosteal grafts from the tibia were the most common method of cranioplasty (Fig. 3). In several papers Villandre reported a total of 130 cases of autograft cranioplasties from various donor sites and concluded that the best results were obtained from osteoperiosteal tibial grafts. ${ }^{27}$ In 1920, Delangeniére published a series of 104 cases of cranioplasty with osteoperiosteal tibial grafts with only two failures. ${ }^{76}$ Around the early 20th century, it became general neurosurgical opinion that autograft cranioplasty was superior to available allografts. ${ }^{59}$

\section{Search for a Suitable Synthetic Material}

Although autograft cranioplasty was most prevalent, the added time, blood loss, and donor site morbidity led many to continue to search for a suitable synthetic material for cranioplasty. The most common synthetic material used during the early 20 th century was celluloid followed distantly by gold and aluminum. Celluloid, created from nitrocellulose and camphor among other compounds, was first described in 1870 . Because celluloid was readily available and easily malleable, several surgeons attempted to use it for cranioplasty. The first cranioplasty with celluloid was described by Fraenkel in $1890 .{ }^{20}$ In 1939, Ney reported 300 cases of celluloid cranioplasty with very good results. ${ }^{48,76}$ However, most other reports were less enthusiastic due to a substantial inflammatory reaction around the implant and subsequent fluid accumulation that required frequent aspiration..$^{54,59,76}$ Gold and, to a lesser extent, platinum were used for cranioplasty, but their use was limited by high cost. ${ }^{27}$ Lead cranioplasty was attempted but resulted in significant tissue toxicity. ${ }^{5}$ Reports of aluminum cranioplasty were marred by high infection rates. ${ }^{11}$ The ideal synthetic material was malleable, strong,

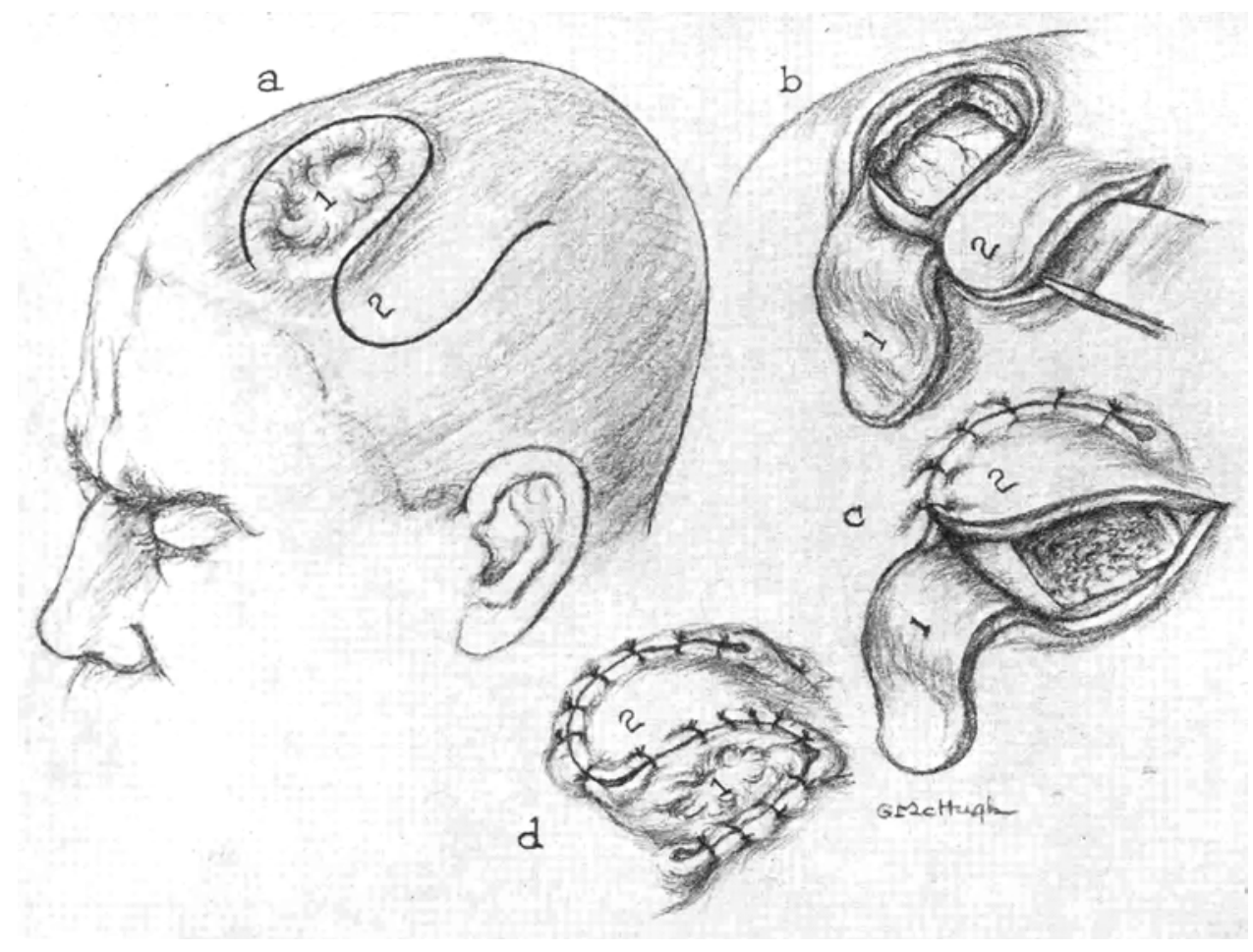

FIG. 1. The Müller-König method. a: An S-shaped incision made around the cranial defect (1) to create a second flap (2) containing scalp, periosteum, and outer table. b: This flap is then rotated to cover the cranial defect. c: The final appearance after closure. d: Cosmesis was generally suboptimal. From Woolf: Int Abstr Surg 81:1-23, 1945. Reproduced with permission from Journal of the American College of Surgeons (formerly Surgery, Gynecology \& Obstetrics). 


\section{History of tantalum cranioplasty}

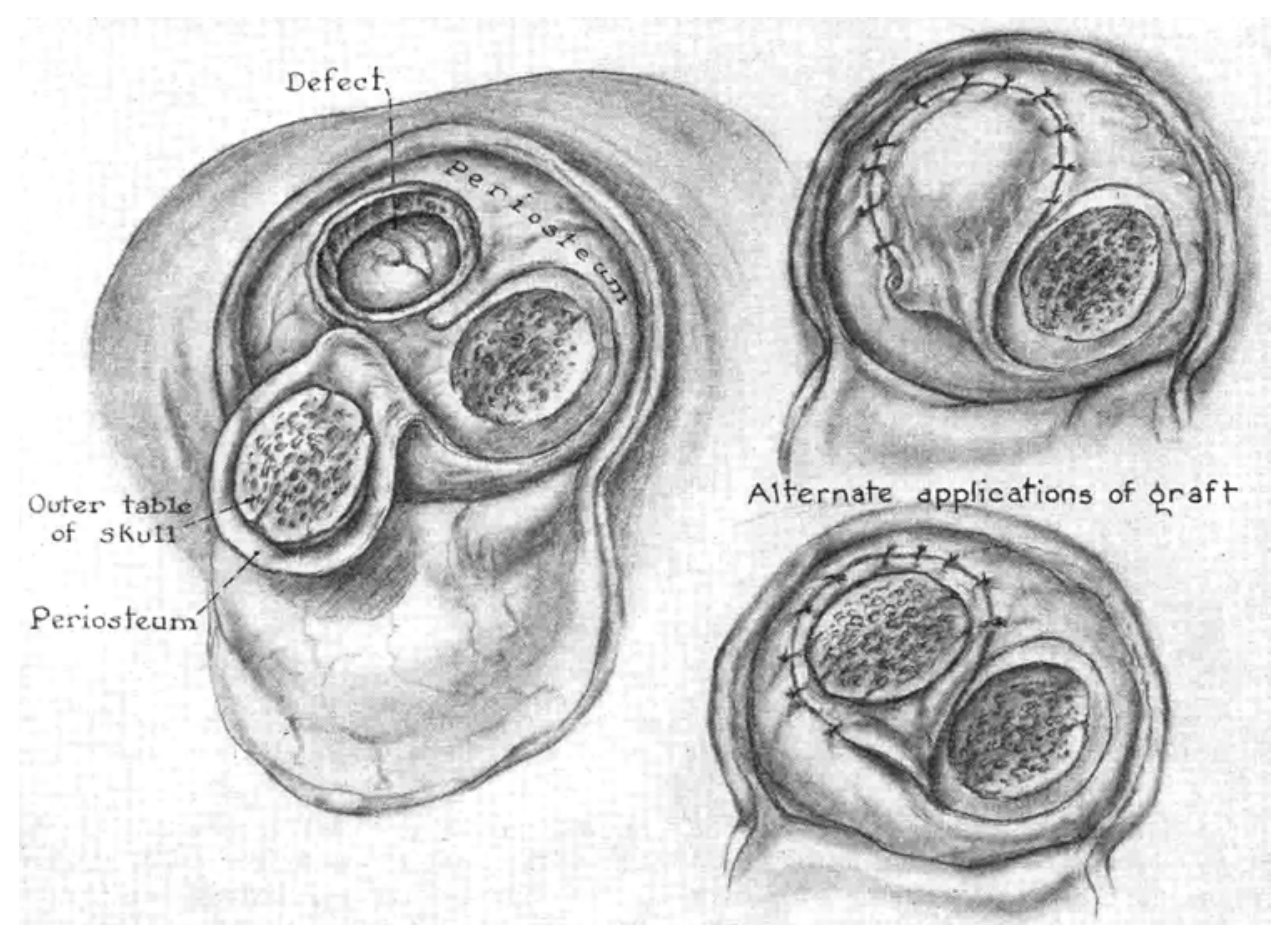

FIG. 2. The von Hacker modification of the Müller-König technique. A single scalp flap is elevated and an osteoperiosteal graft containing outer table only is harvested from the region adjoining the cranial defect (left), rotated into the defect, and sutured (right). From Woolf et al: Int Abstr Surg 81:1-23, 1945. Reproduced with permission from Journal of the American College of Surgeons (formerly Surgery, Gynecology \& Obstetrics).

inert, radiolucent, readily available, and economical. ${ }^{2}$ Despite numerous attempts, cranioplasty utilizing synthetic materials did not gain widespread use because a suitable synthetic material had not yet been discovered.

In the late 1930s, the interest in synthetic cranioplasty was resurrected with the introduction of Vitallium., Experimental and clinical evidence demonstrated little tissue reaction when used in cranioplasty., ${ }^{9,26,52}$ However, there were a few key limitations to Vitallium. First, the Vitallium alloy was associated with a corrosion-induced release of highly toxic chromium salts. Second, Vitallium was not malleable and, therefore, often required an operation to create a "cast" that could be used to shape the Vitallium prosthesis ex vivo and a second operation for implantation of the prosthesis. ${ }^{12}$

\section{Discovery of Tantalum}

Swedish chemist and mineralogist Anders Gustaf Ekeberg (1767-1813) is credited with the discovery of the tantalum in 1802. ${ }^{74}$ The previous year, the element niobium (then called columbium) was discovered by English chemist Charles Hatchett. Due to their high degree of chemical similarity and tendency to be found together, it was not until 1864 that tantalum and niobium would be unequivocally confirmed as separate chemical elements. ${ }^{43}$

Tantalum (chemical symbol Ta, atomic number 73) is a very dense yet malleable metal. Unlike most metals, tantalum is very resistant to corrosion. ${ }^{1}$ The name tantalum is derived from the Greek mythological figure Tantalus, son of Zeus. His punishment for sharing the gods' secrets with mortals is a famous one. In the underworld, he was made to stand in a pool of water up to his neck. Whenever he would lean down to quench his thirst, the water would recede before he was able to take a drink. Accordingly, Ekeberg named his newly discovered element tantalum because upon its submersion in acid, it did not absorb or react with the acid. ${ }^{13,28}$

\section{Experimental Evidence}

The in vivo corrosion of metallic implants occurs as a result of the constant presence of new oxygen molecules in vascularized tissues. Oxidative corrosion of metallic implants used for cranioplasty can cause tissue necrosis primarily due to the liberation of metallic ions from the metal's surface. Therefore, for the purpose of implantation in humans, it appeared critical to find a metal that would either corrode extremely slowly or in a manner that was not injurious to the patient. ${ }^{12}$ In a preliminary report in 1940, Burke began to test the biological inertness of tantalum by placing pieces of the metal in Ringer's solution at body temperature for a 3-month period. The appearance and weight of both the metal and the solution remained unchanged. ${ }^{12}$ In their next experiment, tantalum plates and screws were implanted on the tibia and femur of 6 dogs and rabbits and removed between 3 and 12 weeks later without any noticeable signs of bone or softtissue reaction. ${ }^{12}$ Shortly thereafter, Pudenz confirmed the relative inertness of tantalum by performing experimental tantalum cranioplasties in 11 cats..$^{55}$ One important finding in this animal series was the formation of a 


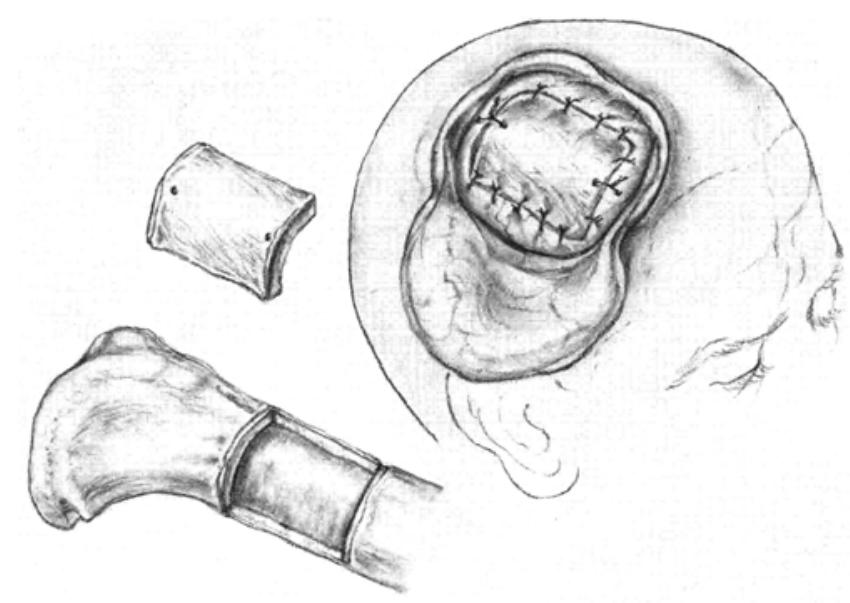

FIG. 3. Osteoperiosteal graft from the patient's tibia is placed in the cranial defect and sutured to the surrounding periosteum. From Woolf et al: Int Abstr Surg 81:1-23, 1945. Reproduced with permission from Journal of the American College of Surgeons (formerly Surgery, Gynecology \& Obstetrics).

connective tissue capsule around the implant. This was actually thought to be a significant advantage at the time because onlay or inlay implantation techniques without fixation were common. Therefore, scar tissue formation could theoretically help prevent implant migration. In none of the cases was the scar tissue compressive, nor did the implant interfere with spontaneous bone regeneration. Most importantly, the tantalum implant remained intact without corrosion.

\section{Clinical Experience}

\section{War Applications}

World War II began in 1939 and the US entered the war after the attack on Pearl Harbor on December 7, 1941. It was estimated that $5.9 \%$ of American World War II casualties were due to head injuries. ${ }^{75}$ The grand scale of the war greatly increased the need for cranioplasty procedures. The clinical problem was aptly described by the neurosurgeon Lieutenant Commander O. Hugh Fulcher in $1943:^{22}$

Cranial defect in military surgery represents a most important problem because of the frequency of occurrence and because it renders a man unfit for military duty unless it can be adequately repaired. Therefore an adequate method of repair is urgent, one which can be performed by the general surgeon as well as by the neurologic surgeon in any ordinary general hospital wherever it may be located. Moreover, the repair should render protection to the intracranial structures against blows, changing atmospheric pressures and changing bodily positions, which should approximate that afforded by the normal cranium. The convalescence following the operative procedure should be brief to keep 'as many men at as many guns as many days as possible'.

Unlike autograft and Vitallium, tantalum greatly simplified the cranioplasty procedure by allowing a single-stage repair in which the implant could be easily cut and shaped with basic instruments. The first recorded use of tantalum for cranioplasty was in the fall of 1941 by Fulcher in the US Naval Hospital in Washington, DC. ${ }^{22}$

\section{P. Flanigan, V. R. Kshettry, and E. C. Benzel}

The operation was successful, and the patient returned to duty 2 months after the operation. After this initial operation, more than 1000 cases of tantalum cranioplasty were performed in the subsequent 5 years. ${ }^{36,67}$

The majority of published case series describing tantalum cranioplasties occurred in the military population (Table 1). A total of 402 patients underwent tantalum cranioplasty in published series alone during World War II. For uncomplicated bony defects, a sheet of tantalum could be molded by the surgeon intraoperatively or molded over a standard skull model preoperatively, followed by minor adjustments intraoperatively. ${ }^{75}$ Hemberger et al. described an elaborate technique for implant formation using various molding materials shaped over the depression in the scalp corresponding to the defect. This "cast" was then used to shape the tantalum plate preoperatively. ${ }^{30}$ For complicated bony defects particularly involving the orbital ridges, the repair was performed in 2 stages. A sterile dental mold was created in the first operation, from which a custom made implant was produced and implanted during a second operation.

\section{Implant Fixation Technique}

Initially, tantalum implant migration was occasionally observed after cranioplasty..$^{14,23,30}$ Loose or migrated plates were also associated with scalp erosion. ${ }^{73}$ Originally, tantalum plates were placed in an onlay fashion and secured by suturing adjacent periosteum or pericranium over the plate. ${ }^{21,22}$ Lewin et al. published the largest clinical series of tantalum cranioplasties (130 cases), performed at the Oxford Military Hospital for Head Injuries. The authors sutured adjacent pericranium or periosteum to perforations made in the plate. ${ }^{37}$ In some cases, they covered the plate with an additional layer of fascia lata that was sutured to surrounding pericranium. They noted that this method was often insufficient for frontal cranioplasties, likely due to the added effect of gravity. In these cases, they used tantalum wire to secure the implant to the calvaria. Many authors adopted 30-gauge tantalum or stainless steel wire instead of suture for such purposes (Fig. 4). ${ }^{30,38,40,42,44,56}$

Before wire and screws became readily available, more involved inlay techniques were also developed to minimize the risk of implant migration (Fig. 5). Simple inlay involved drilling the outer table for a few millimeters beyond the defect to allow the plate to sit in the ledge. ${ }^{14}$ Others bent the edges of the tantalum plate $90^{\circ}$ and seated this ledge into cancellous bone via a groove made through the outer table. ${ }^{30,44,56,75}$ The "inlay with groove" technique was sometimes insufficient alone to prevent migration. ${ }^{56}$ Therefore, this technique was commonly supplemented with tantalum triangular wedges, in which the point was seated into the cancellous bone exposed in the groove and the base was folded over the plate (Fig. 5). ${ }^{30,44,56,75}$ With the various aforementioned techniques, plate migration was relatively uncommon, ranging from $0 \%$ to $5 \%, 3^{30,56,75}$ These studies generally lacked long-term follow-up, so the true incidence of implant migration is not known.

Tantalum screws were generally not available to US military surgeons during World War II. However, 


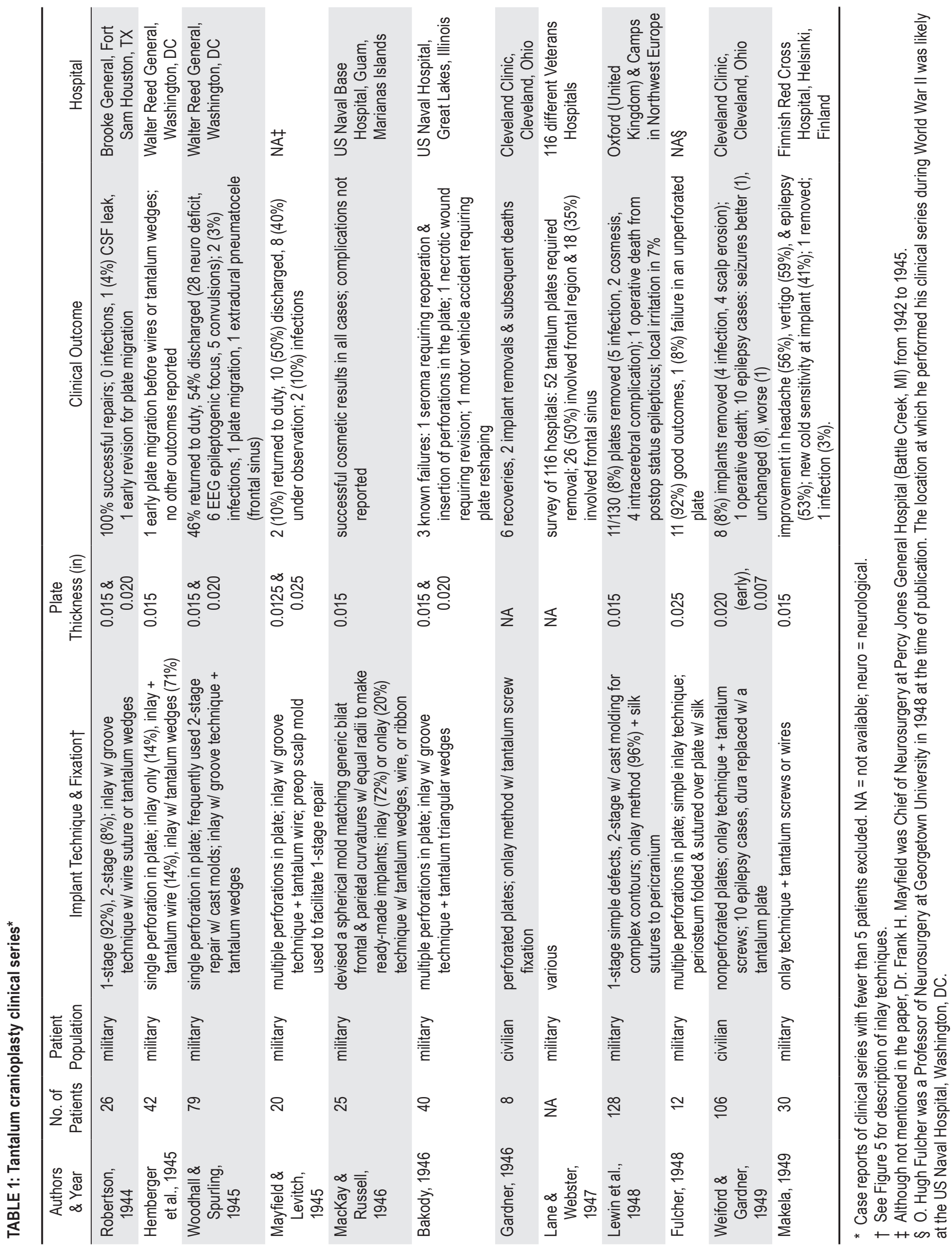




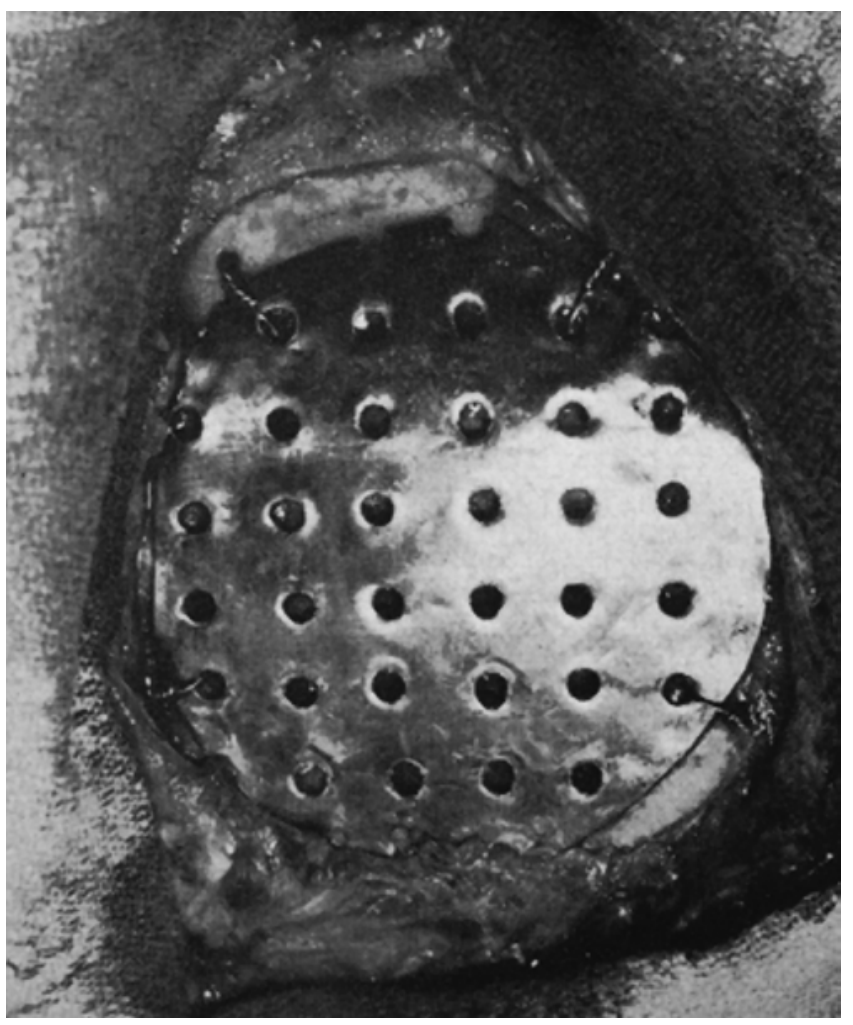

Fig. 4. Tantalum plate secured with stainless steel wire threaded through perforations in the plate and the outer table. Reproduced with permission from Lockhart et al: J Neurosurg 9:254-257, 1952.

shortly after the war, tantalum screws with a simple onlay technique supplanted all prior implantation/fixation techniques due to the speed and ease by which screws could be placed in addition to the superior rigidity they provided. $^{71,73}$

\section{Tantalum Plate Thickness}

During the tantalum cranioplasty era, there was much disagreement regarding the optimal thickness of tantalum plates. Mayfield and Levitch reported that plates $0.125-0.250$ inches in thickness were easily molded and possessed sufficient strength. ${ }^{44}$ Several surgeons believed 0.015 inches was the ideal thickness of a tantalum plate. ${ }^{41,65,75}$ In contrast, Fulcher ${ }^{21,22}$ and Bakody ${ }^{7}$ believed 0.025 inches was necessary to protect the brain. Oscar A. Turner studied the mechanical response of tantalum plates to impact. ${ }^{68} \mathrm{He}$ claimed that the extent of trauma to cranioprostheses had been underplayed in the literature and proposed that a thickness of less than 0.010 inch was insufficient to protect patients against even minor blows (Fig. 6). ${ }^{68}$

On the contrary, Gardner progressively decreased the thickness of the tantalum plates he used from 0.020 to 0.007 inches in his published series of 106 tantalum cranioplasties. ${ }^{71} \mathrm{He}$ believed 0.007 inches to be the optimal thickness because it was less expensive, more malleable, and most importantly, decreased the plate's radiopacity enough to allow pneumoencephalography and angiography (Fig. 7). ${ }^{24}$

\section{a Simple Inlay}

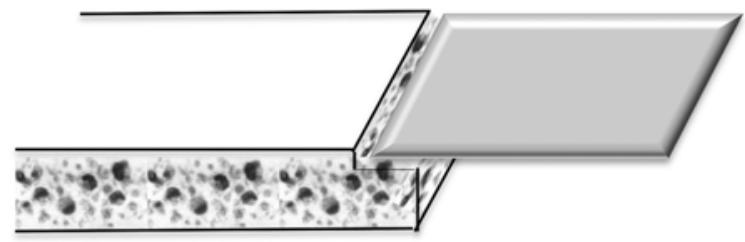

b Inlay with groove

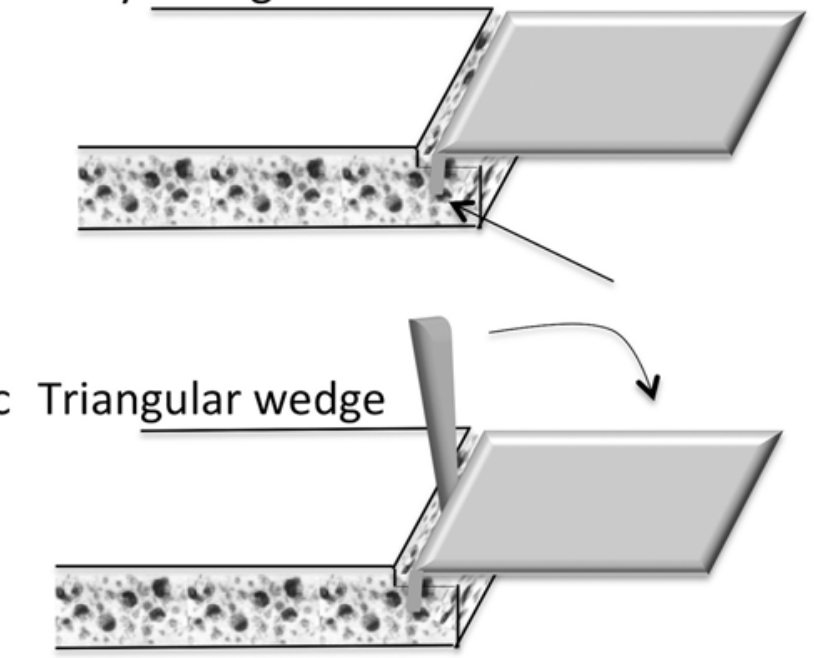

FIG. 5. Inlay techniques. a: Simple inlay: the outer table extending several millimeters beyond the cranial defect was removed to allow the plate to sit in the trough. b: Inlay with groove: a groove through the outer table was chiseled to allow the bent edges of the plate to sit in the groove. c: Triangular wedge: a supplementary fixation technique using triangular wedges with the point driven into the cancellous bone and the base folded over the plate.

\section{Clinical Outcome and Complications}

For studies reporting on infection rates (5 studies, 283 patients), the overall infection rate was $3.5 \% .^{37,42,44,56,75}$ Two studies reported on return to duty outcomes after tantalum cranioplasty. 44,75 The larger of the two studies (79 patients) reported that $46 \%$ of soldiers returned to duty and $54 \%$ were discharged from the military, most commonly due to neurological deficits or either clinical seizures or the presence of an epileptogenic focus on electroencephalography (EEG).$^{75}$ One study in Finland reported on symptomatic outcomes in 30 patients..$^{42}$ Improvements were observed in preoperative headache $(56 \%)$, vertigo $(59 \%)$, and epilepsy $(53 \%)$ after tantalum cranioplasty. However, $41 \%$ of patients experienced new cold sensitivity at the implant site, with one patient requiring implant removal for this reason. The high thermal conductivity of tantalum leading to cold or heat sensitivity was a shortcoming of tantalum that was likely underreported in the literature.

\section{Civilian Applications}

The success neurosurgeons experienced with the use of tantalum for cranioplasty during World War II naturally carried over to the civilian population after the war. W. James Gardner, chief of neurosurgery at the Cleveland 


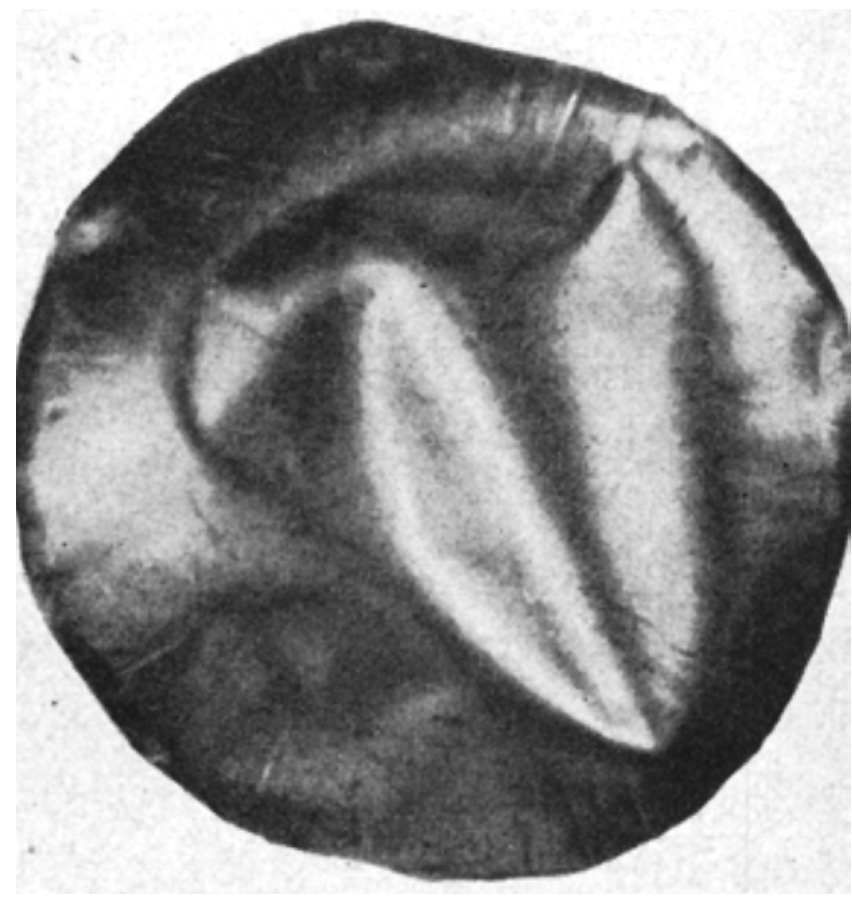

FIG. 6. Removed tantalum plate (0.007 inch) with marked indentation after repeat trauma. Reproduced with permission from Turner: $J$ Neurosurg 9:100-103, 1952.

Clinic, was one of the strongest proponents of tantalum. Gardner, along with Wieford, published the largest civilian population case series (106 patients) of tantalum cranioplasty. ${ }^{71} \mathrm{He}$ used tantalum cranioplasty in 26 old cranial defects, 12 contaminated traumatic defects (Fig. 8), 55 clean operative defects, and 13 infected operative defects. It was generally believed that the indications for cranioplasty for old cranial defects were syndrome of the trephined (headache, dizziness, difficulty concentrating, and fatigue), brain protection, cosmesis, and painful pulsating defects. . $^{6,14,25,27,71}$ Traumatic epilepsy was a controversial indication for cranioplasty. Some authors found that repair had no effect, ${ }^{44}$ whereas others found the opposite. ${ }^{71}$ Gardner reported that 9 of 10 patients with traumatic epilepsy had reduced seizure frequency or were seizure free postoperatively.
Interestingly, Gardner attempted to perform tantalum cranioplasty in 10 patients with nontraumatic Jacksonian epilepsy. In prior tantalum cranioplasties done for other indications, he noticed that postoperative routine EEG demonstrated a reduction in voltage potential. This, combined with the reduction of seizure frequency after tantalum cranioplasty in the traumatic epilepsy population, led Gardner to believe that the tantalum metal possibly had a grounding effect. $^{71}$ In 10 cases, he performed a large frontoparietal craniotomy, resected the dura, and fastened a tantalum plate to the inner table such that when he replaced the bone flap, the plate came into contact with the cortical surface (Fig. 9). Unfortunately, 8 of 10 patients had no change in seizure frequency, and 1 patient actually had more frequent seizures. Postoperative EEG demonstrated a reduction in voltage potential but no change in abnormal delta waves. Gardner concluded that the plate simply caused electrical interference rather than having any effect on cortical electrical activity. He subsequently abandoned this technique.

Two additional applications of tantalum in civilian neurosurgical procedures are worth noting. In 1948, Lester A. Mount described the use of tantalum discs to cover bur holes made with the Hudson brace. ${ }^{46}$ This represented an original form of the bur hole covers commonly used today. The tantalum discs had tabs that were folded down into the bur hole to help prevent the disc from migrating (Fig. 10). Another important application of tantalum in neurosurgery was the use of tantalum dust in craniotomy. Whitcomb and Scoville were the first to report the use of tantalum dust in nervous tissue, which they used to mark the plane of a lobotomy on postoperative radiography. ${ }^{72}$ However, the more common indication for tantalum dust was to diagnose recurrent subdural hematoma using a technique first described by Vieth and colleagues. ${ }^{69} \mathrm{Af}-$ ter surgical evacuation of a subdural hematoma, tantalum dust was sprinkled over the cerebral cortex and a tantalum clip was placed on the dura. The distance between the tantalum dust and clip on an anteroposterior radiograph then served as a measure of the subdural space (Fig. 11).

\section{The Importance of Plate Perforations}

The original tantalum cranioplasty implants consisted of a smooth nonperforated sheet of metal. The
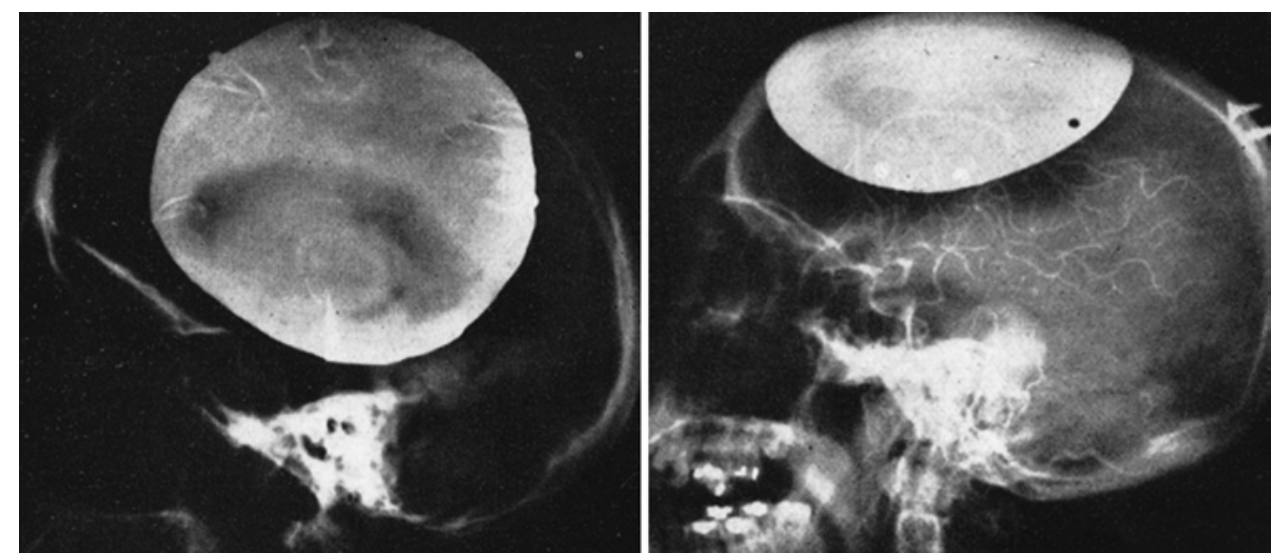

FIG. 7. Pneumoencephalogram with air-filled ventricles (left) and angiography with diodrast-filled vessels (right) easily visualized through a 0.007-inch tantalum implant. Reproduced with permission from Gardner: J Neurosurg 7:590-591, 1950. 

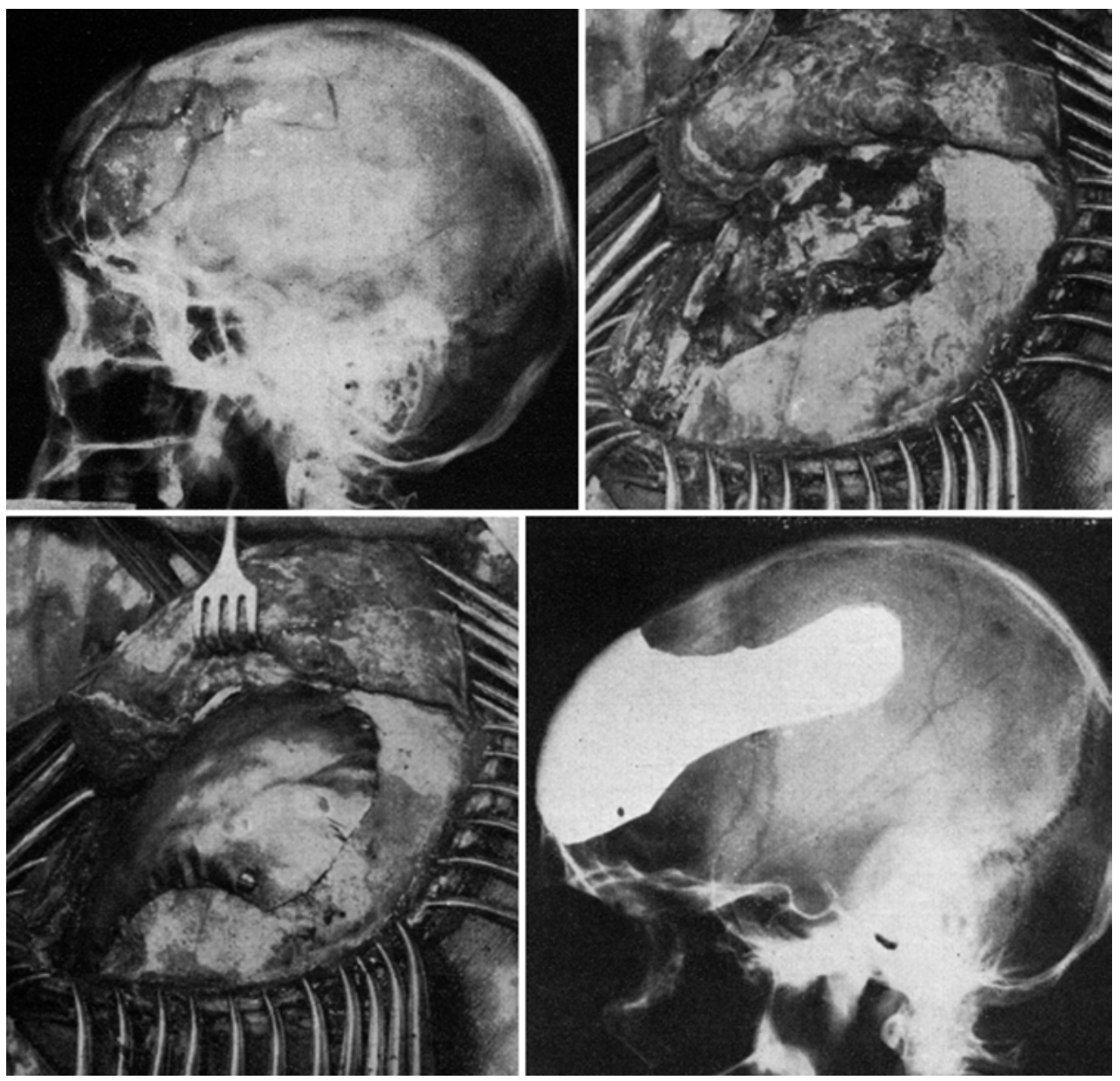

FIG. 8. Civilian gunshot wound from Gardner's case series. Upper Left: Preoperative radiograph demonstrating comminuted left frontal fracture with intraparenchymal shrapnel. Upper Right: Intraoperative appearance during debridement. Lower Left: Nonperforated tantalum plate using onlay technique secured with tantalum screws. Lower Right: Postoperative radiograph demonstrating the radiopaque nature of a 0.020 -inch-thick tantalum plate. Reproduced with permission from Weiford et al: J Neurosurg 6:13-32, 1949.

advantage of this design was that a smooth encapsulated sheath would form around the plate and prevent adhesion to the underlying cortex or dura. This characteristic made it easy to remove the implant when reoperation was nec- essary. However, numerous authors described several advantages of placing multiple perforations in the plate prior to implantation. Before implant fixation techniques were refined, plate migration was a major concern. The use of
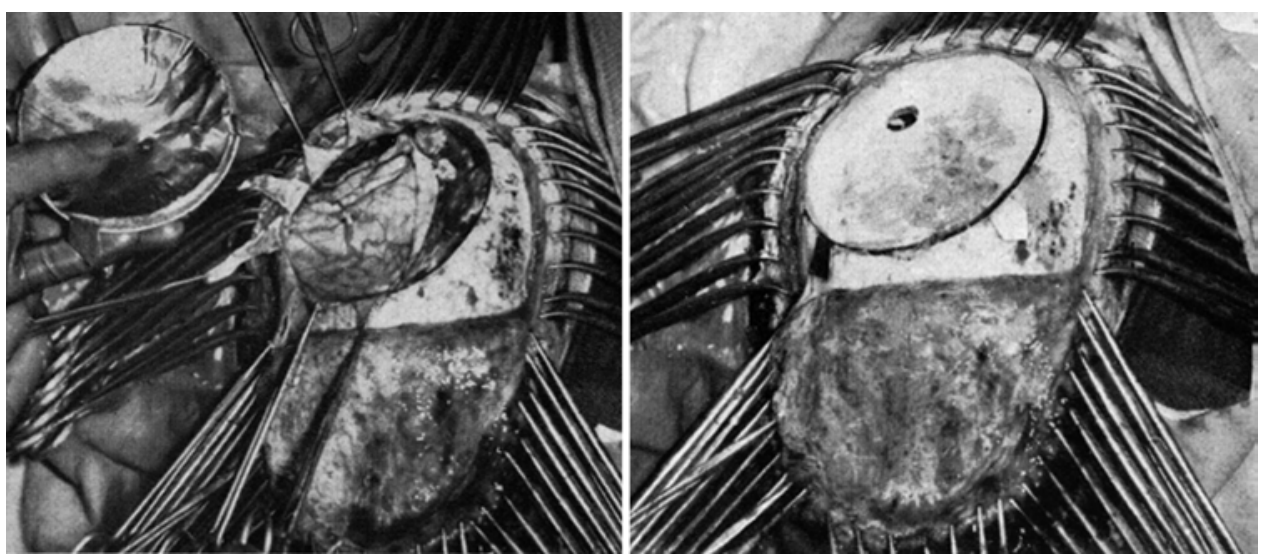

FIG. 9. Gardner's method of tantalum dural replacement for intractable cortical epilepsy. Left: A craniotomy is performed, the dura is resected, and a tantalum plate is fastened to the inner table of the free bone flap. Right: The bone flap is then replaced. Gardner hypothesized the tantalum metal may function to ground aberrant cortical electrical activity. However, after 10 cases, Gardner concluded this method was ineffective. Reproduced with permission from Weiford et al: J Neurosurg 6:13-32, 1949. 

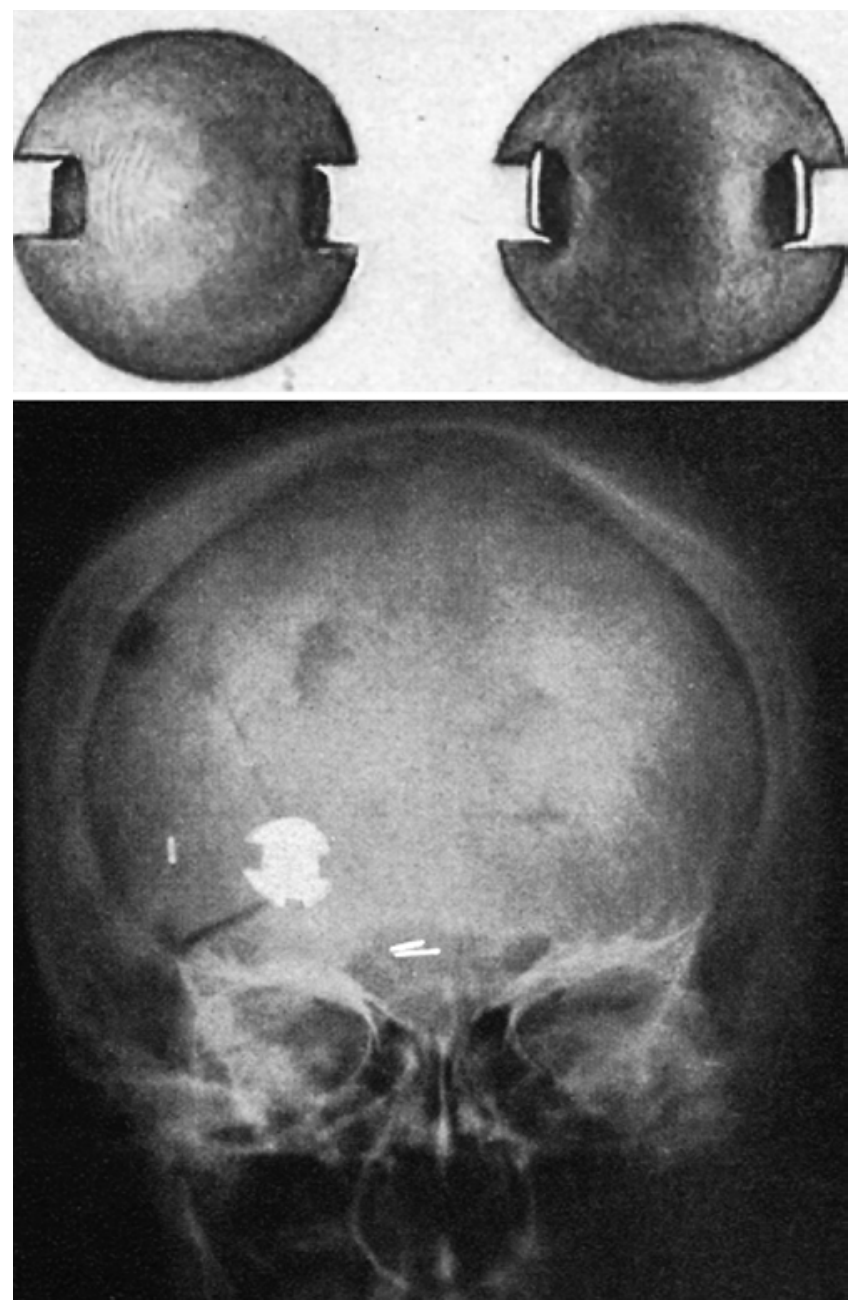

FIG. 10. Upper: Tantalum disc with tabs cut to the width of the bur hole. Lower: Postoperative radiograph with a tantalum disc used to cover the frontal bur hole. Reproduced with permission from Mount: $J$ Neurosurg 5:208-210, 1948.

perforations promoted scar tissue formation between the dura and galea, which helped secure the implant..$^{73}$

The major advantage provided by plate perforations was to simplify the management of postoperative infection. A few authors reported that some postoperative infections could be treated without plate removal by a combination of subgaleal fluid aspiration(s) and both subgaleal and intravenous antibiotics.7,21,25,44,70 Perforations in the plate allowed the epidural and subgaleal fluid to communicate. Therefore, one could aspirate any fluid underneath the plate. ${ }^{73}$ Additionally, soft tissues grew into the perforations during wound healing, which increased the blood supply to the infected area. This also had the advantage of allowing increased antibiotic delivery to the area around the plate. ${ }^{7,21,44,70}$ In fact, some neurosurgeons observed that perforated plates became infected less frequently. ${ }^{44,45}$ Although not known during the tantalum cranioplasty era, it is now known that certain bacteria such as Staphylococcus epidermidis can form biofilms on metal implants that can prevent the penetration of antibiotics..$^{8,29,34,35,50}$ Perforations would also serve to decrease the surface area on which biofilms could form. Today, most titanium cranioplasty implants are either perforated or in a mesh-like pattern.

\section{The Demise of Tantalum and Rise of Acrylics}

Despite its widespread use for cranioplasty during World War II, tantalum use in cranioplasty declined precipitously in the early 1950s. Acrylic (polymers based on acrylic acid) was the primary successor of tantalum for cranioplasty. Research on acrylic cranioplasty began during the early tantalum era in the early 1940s. Prior to the war, acrylic resins were used for dental implants with no observed adverse tissue reactions. ${ }^{75}$ In the decade after World War II, experimental and early clinical reports of acrylic cranioplasty demonstrated a promising safety and efficacy profile. ${ }^{3,10,16,17,19,32,40,49,57,64,66}$ However, it was Spence's report in 1954 that made a strong case for using acrylic rather than tantalum for cranioplasty. ${ }^{64}$ Spence convincingly detailed the personal, economic, and medical shortcomings of metal plates. First, there existed a significant social stigma associated with having metal in one's head. Second, tantalum was very costly to manufacture. Third, several authors hypothesized that postoperative headaches and local heat or cold sensitivity could be due to the high thermal conductivity of tantalum..$^{5,42,73}$ Finally, the radiopacity of tantalum remained at least a moderate hindrance to meaningful postoperative diagnostic imaging. Acrylics overcame all these limitations.

Spence reported favorable results with polymethylmethacrylate (PMMA) ${ }^{64}$ Unlike metals, PMMA facilitated the filling of cranial defects, which Spence believed prevented brain herniation into the dead space of the cranial defect. Although initially seen as an advantage, the radiolucency of PMMA actually presented a clinical dilemma. In cases of repeat trauma, radiography could not be used to diagnose implant fracture or the displacement of fragments. ${ }^{31}$ Eventually, a small amount of barium was added to the commercially available PMMA mixtures to allow adequate imaging of the implant while maintaining sufficient radiolucency to avoid interference with angiographic imaging. ${ }^{31}$

Polymethylmethacrylate did have its limitations, such as the inhibition of bone growth, and some interest in metals remained. Some authors favored stainless steel because it was also malleable, yet was less than $1 \%$ of the cost of tantalum. ${ }^{61,62}$ Titanium, first used for cranioplasty by Simpson in 1965, eventually became the metal of choice and completely halted the production of tantalum cranioprostheses. ${ }^{63}$

\section{Conclusions}

The World War II era heralded a renaissance for cranioplasty. The enormous scale of the war greatly increased the demand for cranioplasty procedures. Tantalum provided a major breakthrough in synthetic cranioplasty as it was strong, readily available, malleable, and biologically inert. This enabled military neurosurgeons to repair cranial defects expeditiously in a single stage without the donor site morbidity of autograft. The surgical technique, particularly in regard to implant fixation, was refined during the war. These developments represent a lasting con- 

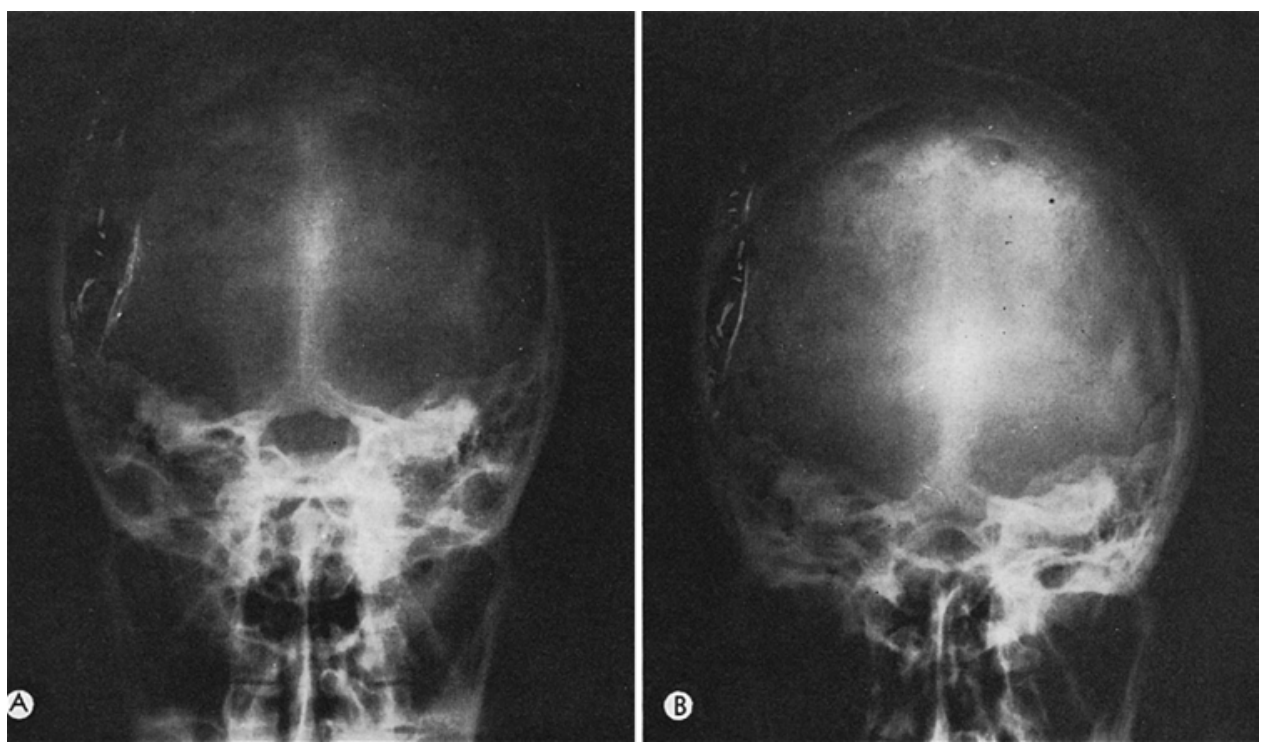

FIG. 11. A: Postoperative anteroposterior radiograph obtained after subdural hematoma evacuation. Tantalum dust is sprinkled onto the cortical surface, and tantalum clips are placed onto the dura to approximate the dimensions of the subdural space. B: After several months, a decrease in subdural space is evidenced by decreasing the distance between the tantalum dust and clips. Reproduced with permission from Vieth et al: J Neurosurg 24:514-519, 1966.

tribution to the field of neurosurgery. Finally, the limitations of tantalum further defined the attributes of the ideal synthetic material for cranioplasty and pushed scientists and neurosurgeons to search for better materials.

The lessons learned from this historical vignette can inform modern innovation in cranioplasty materials and techniques. We must learn from those who preceded us, lest we become doomed to repeat their mistakes.

\section{Disclosure}

The authors report no conflict of interest concerning the materials or methods used in this study or the findings specified in this paper.

Author contributions to the study and manuscript preparation include the following. Conception and design: Kshettry. Acquisition of data: Kshettry, Flanigan. Analysis and interpretation of data: Kshettry, Flanigan. Drafting the article: all authors. Critically revising the article: all authors. Reviewed submitted version of manuscript: all authors. Approved the final version of the manuscript on behalf of all authors: Kshettry. Study supervision: Benzel.

\section{References}

1. Agulyansky A: The Chemistry of Tantalum and Niobium Fluoride Compounds. Amsterdam: Elsevier, 2004

2. Alberstone C, Benzel E: Cranioplasty materials, in Rengachary SS, Benzel EC (eds): Calvarial and Dural Reconstruction. Park Ridge, IL: American Association of Neurological Surgeons, 1998, pp 35-46

3. Alexander E Jr, Dillard PH: The use of pure polyethylene plate for cranioplasty. J Neurosurg 7:492-498, 1950

4. Asenjo A: Neurosurgical Techniques. Springfield, IL: Charles C Thomas, 1963

5. Aydin S, Kucukyuruk B, Abuzayed B, Aydin S, Sanus GZ: Cranioplasty: review of materials and techniques. J Neurosci Rural Pract 2:162-167, 2011

6. Baker GS: Cranioplasty with tantalum plate in the postwar period. Surg Clin North Am 26:841-845, 1946

7. Bakody JT: Tantalum cranioplasty. Ohio Med 42:29-33, 1946
8. Barth E, Myrvik QM, Wagner W, Gristina AG: In vitro and in vivo comparative colonization of Staphylococcus aureus and Staphylococcus epidermidis on orthopaedic implant materials. Biomaterials 10:325-328, 1989

9. Beck CS: Repair of defects in skull by ready made vitallium plates. JAMA 118:798-799, 1942

10. Blaine G, Oliver LC: A simplified one-stage method of cranioplasty with acrylic resin. Br J Surg 39:371-372, 1952

11. Booth JA, Curtis BF: I. Report of a case of tumor of the left frontal lobe of the cerebrum; operation; recovery. Ann Surg 17:127-139, 1893

12. Burke GL: The corrosion of metals in tissues; and an introduction to tantalum. Can Med Assoc J 43:125-128, 1940

13. Colakis M, Masello MJ: Classical Mythology \& More: A Reader Workbook. Mundelein, IL: Bolchazy-Carducci Publishers, 2007

14. Dahleen HC: Tantalum cranioplasty, a method for one-piece fixation. Surgery 21:546-555, 1947

15. Dobrotworski WJ: Die rippen als material zur knochenautoplastik. Zentralbl Chir 32:1081-1083, 1911

16. Dodge HW, Craig WM: Acrylic cranioplasty; a newer rapid method for the repair of cranial defects; preliminary report. Proc Staff Meet Mayo Clin 28:256-257, 1953

17. Elkins CW, Cameron JE: Cranioplasty with acrylic plates. J Neurosurg 3:199-205, 1946

18. Ella S: Native medicine and surgery in the South Sea Islands. Med Times 1:50-51, 1874

19. Ertevtsian LN: [Plastic repair of extensive cranial defects with polymethylmetacrylate.] Sov Med 2:22, 1951 (undetermined language)

20. Fraenkel A: Ueber deckung von trepanationsdefekten am schädel durch heteroplastik. Wien Klin Wochenschr 3:475476, 1890

21. Fulcher OH: Cranioplasty; a technic with tantalum. Med Ann Dist Columbia 17:485-492, 1948

22. Fulcher $\mathrm{OH}$ : Tantalum as a metallic implant to repair cranial defects. JAMA 121:931-933, 1943

23. Gardner W: Closure of defects of the skull with tantalum. Surg Gynecol Obstet 80:303-312, 1945

24. Gardner WJ: Encephalography in the presence of a tantalum implant. J Neurosurg 7:590-591, 1950 
25. Gardner WJ: The use of tantalum for repair of cranial defects in infected cases. Cleve Clin Q 13:72-87, 1946

26. Geib FW: Vitallium skull plates. JAMA 117:8-12, 1941

27. Grant FC, Norcross NC: Repair of cranial defects by cranioplasty. Ann Surg 110:488-512, 1939

28. Greenwood NN, Earnshaw A: Chemistry of the Elements, ed 2. Burlington, MA: Elsevier Butterworth-Heinemann, 1997, p 1138

29. Gristina AG: Biomaterial-centered infection: microbial adhesion versus tissue integration. Science 237:1588-1595, 1987

30. Hemberger AJ, Whitcomb BB, Woodhall B: The technique of tantalum plating of skull defects. J Neurosurg 2:21-25, 1945

31. Henry HM, Guerrero C, Moody RA: Cerebrospinal fluid fistula from fractured acrylic cranioplasty plate. Case report. J Neurosurg 45:227-228, 1976

32. Kleinschmidt O: Plexiglas zur deckung von schädellücken. Chirurg 13:273-277, 1941

33. König F: Der knöcherne ersatz großer schädeldefekte. Central Chir 27:497-501, 1890

34. Kshettry VR, Angelov L: Technical note regarding immediate titanium mesh cranioplasty for post-craniotomy infections. World Neurosurg [epub ahead of print], 2013 (Letter)

35. Kshettry VR, Hardy S, Weil RJ, Angelov L, Barnett GH: Immediate titanium cranioplasty after debridement and craniectomy for postcraniotomy surgical site infection. Neurosurgery 70 (1 Suppl Operative):8-15, 2012

36. Lane S, Webster JE: A report of the early results in tantalum cranioplasty. J Neurosurg 4:526-529, 1947

37. Lewin W, Graham MP, Northcroft GB: Tantalum in the repair of traumatic skull defects. Br J Surg 36:26-41, 1948

38. Lockhart WS Jr, Van Den Noort G, Kimsey WH, Groff RA: A comparison of polyethylene and tantalum for cranioplasty. A preliminary report. J Neurosurg 9:254-257, 1952

39. Macewen W: An address on the surgery of the brain and spinal cord. Br Med J 2:302-309, 1888

40. Mackay HJ: A method of cranioplasty using ready-made acrylic cranioprostheses. Surgery 22:965-975, 1947

41. MacKay HJ, Russell LA: A method of cranioplasty using a readymade tantalum cranioprosthesis. Surgery 20:830-844, 1946

42. Makela T: Tantalum cranioplasty of war wounds of the skull. Ann Chir Gynaecol Fenn 38:13-19, 1949

43. Marignac B, Deville H, Troost L, Hermann R: Tantalsäure, niobsäure, (ilmensäure) und titansäure. Zeitschrift für Analytische Chemie 5:384-389, 1866

44. Mayfield FH, Levitch LA: Repair of cranial defects with tantalum. Am J Surg 67:319-332, 1945

45. Meirowsky AM, Hazouri LA, Greiner DJ: Epidural granulomata in the presence of tantalum plates. J Neurosurg 7:485491, 1950

46. Mount LA: Tantalum discs for covering trephine defects and tantalum clips for ligation of internal carotid artery intracranially. J Neurosurg 5:208-210, 1948

47. Müller P: Deckung von schädeldefekten aus dem sternum. Zentralbl Chir 23:409-410, 1915

48. Ney KW: The repair of cranial defects with celluloid. Am J Surg 44:394-399, 1939

49. Niederle B: [Cranioplasty with plexiglass.] Rozhl Chir 29:393-401, 1950 (undetermined language)

50. Oga M, Sugioka Y, Hobgood CD, Gristina AG, Myrvik QN: Surgical biomaterials and differential colonization by Staphylococcus epidermidis. Biomaterials 9:285-289, 1988

51. Pankratiev BE: Dead bone grafts to repair skull defects. Ann Surg 97:321-326, 1933

52. Peyton WT, Hall HB: The repair of a cranial defect with a vitallium plate. Surgery 10:711-715, 1941
53. Piggot S: A trepanned skull of the Beaker period from Dorset and the practice of trepanning in prehistoric Europe. Proc Prehist 6:112-132, 1940

54. Pringle JH: Remarks on the closure of gaps in the skull, with notes of cases. Br Med J 1:246-248, 1906

55. Pudenz RH: The repair of cranial defects with tantalum: an experimental study. JAMA 121:478-481, 1943

56. Robertson RCL: Repair of cranial defects with tantalum. J Neurosurg 1:227-236, 1944

57. Robinson RG, Macalister AD: Acrylic cranioplasty: a simple one-stage method using a cold curing material. Br J Surg 42:312-315, 1954

58. Röpke W: Zur frage der deckung von schädeldefekten. Zentralbl Chir 35:1192-1194, 1912

59. Sanan A, Haines SJ: Repairing holes in the head: a history of cranioplasty. Neurosurgery 40:588-603, 1997

60. Sanan A, Rengachary SS: History of calvarial reconstruction, in Rengachary SS, Benzel EC (eds): Calvarial and Dural Reconstruction. Park Ridge, IL: American Association of Neurological Surgeons, 1998, pp 1-22

61. Scott M, Urycis HT: Experimental observations on the use of stainless steel for cranioplasty; a comparison with tantalum. Arch Neurol Psychiatry 56:594, 1946

62. Scott M, Wycis HT: Experimental observations on the use of stainless steel for cranioplasty: a comparison with tantalum. J Neurosurg 3:310-317, 1946

63. Simpson D: Titanium in cranioplasty. J Neurosurg 22:292293, 1965

64. Spence WT: Form-fitting plastic cranioplasty. J Neurosurg 11:219-225, 1954

65. Canfield N: Tantalum implants for skull defects. Proc R Soc Med 38:293-298, 1945

66. Trapozzano VR, Grant FC, Spitz EB: Acrylic cranioplasty. Oral Surg Oral Med Oral Pathol 1:815-826, 1948

67. Turner OA: Tantalum cranioplasty. Ohio Med 42:604-607, 1946

68. Turner OA: Tantalum cranioplasty and repeated trauma. J Neurosurg 9:100-103, 1952

69. Vieth RG, Tindall GT, Odom GL: The use of tantalum dust as an adjunct in the postoperative management of subdural hematomas. J Neurosurg 24:514-519, 1966

70. Voris RC: The repair of skull defects with special reference to the use of tantalum. Surg Clin North Am Feb:33-55, 1946

71. Weiford EC, Gardner WJ: Tantalum cranioplasty; review of 106 cases in civilian practice. J Neurosurg 6:13-32, 1949

72. Whitcomb BB, Scoville WB: Methods of marking the plane of section in the open lobotomy operation. Radiology 54:741742,1950

73. White JC: Late complications following cranioplasty with alloplastic plates. Ann Surg 128:743-754, 1948

74. Wollaston WH: On the identity of columbium and tantalum. Philos Trans R Soc Lond 99:246-252, 1809

75. Woodhall B, Spurling RG: Tantalum cranioplasty for war wounds of the skull. Ann Surg 121:649-668, 1945

76. Woolf JI, Walker AE: Cranioplasty: collective review. Int Abstr Surg 81:1-23, 1945

Manuscript submitted December 9, 2013.

Accepted February 12, 2014.

Please include this information when citing this paper: DOI: 10.3171/2014.2.FOCUS13552.

Address correspondence to: Varun R. Kshettry, M.D., Neurological Institute, S-40, Cleveland Clinic, 9500 Euclid Ave., Cleveland, OH 44195. email kshettv@ccf.org. 